\title{
PORTUGUÊS COMO LÍNGUA DE ACOLHIMENTO PARA VENEZUELANOS(AS): ESTRATÉGIAS E PRÁTICAS DE ENSINO EM TEMPOS DE PANDEMIA
}

\author{
PORTUGUÉS COMO LENGUA DE ACOGIDA PARA VENEZOLANOS(AS): \\ ESTRATEGIAS Y PRÁCTICAS DE ENSEÑANZA EN TIEMPOS DE PANDEMIA
}

\author{
PORTUGUESE AS A HOST LANGUAGE FOR VENEZUELANS: TEACHING \\ STRATEGIES AND PRACTICES IN TIMES OF PANDEMICS.
}

\author{
Lígia Soares SENE ${ }^{1}$ \\ Tainara Lucia Corrêa de MATOS ${ }^{2}$ \\ Rosângela Sanches da Silveira GILENO ${ }^{3}$
}

RESUMO: Devido à crise sanitária da COVID-19 que afligiu o mundo no início de 2020, os cursos de ensino-aprendizagem de línguas no Brasil têm (re)criado estratégias de ensino para a sua oferta on-line. Neste texto, apresentamos as estratégias de ensino-aprendizagem desenvolvidas, em 2020, pelo projeto Português como Língua de Acolhimento para venezuelanos(as), ofertado pelo Centro de Línguas e Desenvolvimento de Professores da Faculdade de Ciências e Letras da Unesp de Araraquara. O projeto teve por objetivo oferecer, gratuitamente, o ensino emergencial e remoto de Português, variante brasileira, a estudantes venezuelanos(as), tanto para adultos quanto para crianças, que estavam instalados no interior de São Paulo. Este texto está dividido em três partes: na primeira, trazemos a trajetória do ensino presencial para o on-line; na segunda, descrevemos as estratégias de ensino e apresentamos o perfil dos estudantes; e na terceira, apresentamos a avaliação que esses fizeram sobre as estratégias de ensino.

PALAVRAS-CHAVE: Ensino on-line. Português como Língua de Acolhimento. Estratégias de ensino.

RESUMEN: Debido a la crisis sanitaria de COVID-19 que afectó al mundo a principios de 2020, los cursos de enseñanza y aprendizaje de idiomas en Brasil han (re) creado estrategias de enseñanza para su oferta en línea. En este texto, presentamos las estrategias de enseñanza-aprendizaje desarrolladas, en 2020, por el proyecto Portugués como Lengua de Acogida para Venezolanos (as), ofrecido por el Centro de Idiomas y Desarrollo de profesores de la Facultad de Ciencias y Letras de Unesp en Araraquara. El proyecto tenía como objetivo

\footnotetext{
1 Universidade Estadual Paulista (UNESP), Araraquara - SP - Brasil. Doutoranda no Programa de PósGraduação em Linguística e língua Portuguesa. ORCID: https://orcid.org/0000-0002-3647-6452. E-mail: portuguesligiasene@gmail.com

${ }^{2}$ Universidade Estadual Paulista (UNESP), Araraquara - SP - Brasil. Mestranda no Programa de Pós-Graduação em Linguística e Língua Portuguesa. ORCID: https://orcid.org/0000-0003-3053-2043. E-mail: tainara.matos@unesp.br

${ }^{3}$ Universidade Estadual Paulista (UNESP), Araraquara - SP - Brasil. Professora Assistente no Departamento de Educação. Doutorado em Letras (UNESP). ORCID: https://orcid.org/0000-0002-9994-5009. E-mail: rosangela.gileno@unesp.br
} 
ofrecer, de forma gratuita, la enseñanza remota y de emergencia de portugués, variante brasileña, a estudiantes venezolanos, tanto para adultos como para niños, que vivían en el interior de São Paulo. Este texto se divide en tres partes: en la primera, presentamos la trayectoria de las clases en el aula a clases en línea; en la segunda, describimos las estrategias de enseñanza y presentamos el perfil de los estudiantes; y en la tercera, la valoración que hicieron sobre las estrategias de enseñanza.

PALABRAS CLAVE: Enseñanza en línea. Portugués como lengua de acogida. Estrategias de enseñanza.

ABSTRACT: Due to the COVID-19 health crisis that afflicted the world in early 2020, language teaching and learning courses in Brazil have (re)created teaching strategies for online offer. In this text, we present the teaching-learning strategies developed, in 2020, by the project Portuguese as a Host Language for Venezuelans, offered by the Center for Languages and Teacher Development of the Faculty of Sciences and Letters of Unesp in Araraquara. The project aimed to offer, free of charge, emergency and remote teaching of Portuguese, Brazilian variant, to Venezuelan students, both for adults and children, who were living in the interior of São Paulo. This text is divided into three parts: in the first, we bring the trajectory of classroom teaching to online; in the second, we describe the teaching strategies and present the profile of the students; and in the third, the assessment they made about the teaching strategies.

KEYWORDS: Online teaching. Portuguese as a Host Language. Teaching strategies.

\section{Introdução}

Este texto foi escrito com a finalidade de compartilhar as ações desenvolvidas pela equipe do projeto Português como Língua de Acolhimento para Venezuelanos(as) em sua oferta on-line, recebendo para essa versão o nome de PLAc on-line. O projeto está integrado ao Centro de Línguas e Desenvolvimento de Professores da Faculdade de Ciências e Letras da Unesp de Araraquara e tem por objetivo ofertar o ensino-aprendizagem da Língua Portuguesa, variante brasileira, a pessoas que se encontram em deslocamento forçado e residem no interior de São Paulo.

A escrita deste texto é realizada pelas atuais coordenadoras do projeto. Os dados apresentados neste trabalho foram gerados ao longo do ano de 2020 por meio da aplicação de dois questionários. Ressaltamos que, para tratar, organizar e interpretar os dados gerados por esses documentos, nos apropriamos de procedimento da análise documental que de acordo com Bardin (2016, p. 51) "tem por objetivo dar forma conveniente e representar de outro modo essa informação, por intermédio de procedimentos de transformação". O propósito desse método é "o armazenamento sob uma forma variável e a facilitação do acesso ao 
observador, de tal forma que este obtenha o máximo de informação (aspecto quantitativo), com máximo de pertinência (aspecto qualitativo)" (BARDIN, 2016, p. 51).

Ao que concerne às estratégias de ensino aqui apresentadas, compreendemos essas como as ações selecionadas, elaboradas, criadas por um(a) professor(a), equipe, instituição para atingir a determinados objetivos de aprendizagem. Dessa forma, as estratégias de ensino apresentadas neste texto consistem nas escolhas e ações que a equipe do projeto realizou durante o ano de 2020.

As práticas pedagógicas e as estratégias de ensino do projeto tanto na sua oferta presencial quanto na on-line foram criadas e desenvolvidas pela perspectiva das teorias, pesquisas e experiências resultantes da modalidade de Português como Língua de Acolhimento (PLAc). Essa modalidade de ensino, no Brasil, tem sido comumente aplicada em contexto de migração e, recentemente, ao contexto de estudantes indígenas. $\mathrm{O}$ ensino de Português pela perspectiva do PLAc, conforme Grosso (2010), Amado (2013), São Bernardo (2016), Barbosa e São Bernardo (2017), Sene (2017, 2019) objetiva, em primeiro momento, desenvolver a competência linguístico-comunicativa dos estudantes juntamente com o letramento de práticas socioculturais, a fim de que esses consigam movimentar-se social e culturalmente na sociedade em que estão vivendo. Com o intuito de atingir esses objetivos, é necessário criar/selecionar estratégias de ensino e práticas pedagógicas que sejam adequadas ao contexto e às necessidades dos estudantes.

Contudo, é preciso compreender que cada contexto de ensino é diferente e assim demanda dinâmicas, estratégias e práticas pedagógicas específicas. A especialidade do PLAc tem contribuído para reforçar a prática e a necessidade de olhar para o contexto e para as necessidades dos estudantes para então gerir todo o ensino e suas materialidades (material didático, procedimentos de experienciar a língua e avaliação da proficiência). Outra contribuição dessa especialidade de ensino, de acordo com Lopez e Diniz (2018), é a transdisciplinaridade com outras áreas que essa modalidade possibilita e necessita ao ser construída e conduzida.

Dessa forma, o ensino conduzido pelo projeto Português como Língua de Acolhimento para Venezuelanos(as) tem se fundamentado nas propostas e pesquisas desenvolvidas no âmbito de PLAc de maneira a aprender com as práticas e estratégias já realizadas e, assim, atualizá-las ou mesmo recriá-las para que atendam de maneira adequada, respeitosa e afetuosa, ao contexto de ensino on-line de Português aos estudantes do projeto. 
A seguir, discorremos sobre as estratégias de ensino desenvolvidas no projeto. Para isso, trazemos um breve panorama das estratégias na oferta presencial do projeto e, em seguida, nos aprofundamos na descrição e análise das estratégias na oferta on-line.

\section{Trajetória do presencial para o on-line}

O projeto Português como Língua de Acolhimento para Venezuelanos(as) se iniciou em novembro de 2018 na cidade de Araraquara, interior de São Paulo. Em parceria com o Centro de Línguas e Desenvolvimento de Professores da Faculdade de Ciências e Letras da Unesp de Araraquara, a Prefeitura Municipal de Araraquara, a Diretoria de Ensino e os membros da Igreja de Jesus Cristo dos Santos dos Últimos Dias, o projeto pôde atender em sua oferta presencial (2018 a 2019) uma média de 100 estudantes venezuelanos.

Foram ofertados cursos presenciais de Português, na variante brasileira, para o público adulto, nível básico (AC1) e nível intermediário (AC2), e para o público das crianças, PLAczinho Baby (crianças não-alfabetizadas) e PLAczinho Maior (crianças alfabetizadas).

As estratégias de ensino, as dinâmicas pedagógicas e didáticas planejadas e executadas pela equipe do projeto foram criadas a partir dos recursos humanos e físicos disponíveis tendo em vista atender, de maneira mais adequada, o contexto de ensino, a faixa etária dos estudantes e as necessidades apresentadas por eles na aprendizagem do Português. Dessa maneira, foram organizadas aulas temáticas, atividades interculturais e momentos de incentivo e acesso a livros.

As aulas e as atividades eram planejadas conforme os temas escolhidos pelos aprendentes. Os estudantes, ao ingressarem no curso, preenchiam um questionário com 35 perguntas (fechadas e abertas). A partir dos resultados desse questionário, planejamos e elaboramos a dinâmica do curso e as materialidades de ensino, tais como o planejamento das aulas, os materiais didáticos, os procedimentos para experiência e a avaliação da aprendizagem da língua-alvo.

Para o público infantil do PLAczinho Baby e PLAczinho Maior no formato presencial, o planejamento e a elaboração das aulas foram realizadas de maneira a atender adequadamente a faixa etária das crianças para o desenvolvimento de aspectos linguístico, social, afetivo, intercultural e motor. Para isso, a equipe de professores composta por graduandos(as) e pós-graduandos(as) em Pedagogia e Letras, se utilizou de criações de projetos temáticos que tiveram por objetivo principal proporcionar nas aulas um acolhimento e um espaço com condições favoráveis à aprendizagem tanto do Português quanto da língua- 
materna das crianças, que no caso era o Espanhol. Também foram realizadas atividades interculturais com as crianças, assim como a oferta de livros e o incentivo à leitura em Língua Portuguesa, com textos adequados para cada idade.

Para conhecer em mais detalhes a trajetória e estratégias do ensino presencial do projeto Português como Língua de Acolhimento para Venezuelanos(as), consulte o artigo "O ensino de Português como Língua de Acolhimento (PLAc) para venezuelanos no interior paulista: trajetória e perspectiva" (FIORELLI et al., 2021) ${ }^{4}$.

Em março de 2020, todo o Brasil se viu preso em uma mesma situação: a pandemia da COVID-19 chega ao país e obriga todos a reconfigurarem seus modos de vida. Isso aconteceu também em ambientes de ensino. O ano letivo de 2020 não pôde começar como havíamos planejado.

Neste período, era uma preocupação de toda a equipe do projeto o desfalque no suporte linguístico que os alunos teriam se as aulas parassem por completo. Portanto, no final do mês de março de 2020, a equipe se reuniu para pensar nas estratégias que poderiam ser tomadas neste momento ainda tão desconhecido para todos. Nasce, então, a ideia do Português como Língua de Acolhimento on-line - PLAc on-line.

Inicialmente, foram abertos dois grupos no aplicativo de conversas WhatsApp, criando, assim, um meio de comunicação mais rápido com os alunos. Um deles, destinado aos adultos e, o outro, destinado ao público infantil, representado pelas figuras dos pais. Os estudantes foram então avisados da nova ação do projeto e convidados a participar dos grupos.

A primeira reunião da equipe do PLAc on-line aconteceu no dia primeiro de abril. Neste momento, a equipe contava com 20 voluntários, sendo 14 professores (alunos(as) das graduações em Letras e em Pedagogia e alunos(as) da pós-graduação em Linguística e Língua Portuguesa da Unesp de Araraquara), duas coordenadoras (doutorandas em Linguística e Língua Portuguesa) e duas supervisoras (professoras da Faculdade de Ciências e Letras da Unesp).

\section{Estratégias de ensino on-line}

As estratégias de ensino on-line foram criadas com o objetivo de continuar auxiliando os estudantes venezuelanos com o ensino e aprendizagem do Português e com informações,

\footnotetext{
${ }^{4}$ Este texto está disponível nas referências deste artigo Fiorelli et al. (2021)
} 
conhecimentos e letramentos sociais sobre assuntos relacionados aos cuidados, segurança e acesso a direitos durante o isolamento social que vivemos em decorrência da pandemia.

Dentre as estratégias de ensino pensadas inicialmente para continuar com a oferta do ensino e aprendizagem de Português tanto para o grupo dos adultos quanto das crianças, a equipe de pronto descartou a possibilidade de realização de encontros síncronos, visto que, pela experiência e observação na oferta presencial com o grupo de alunos do projeto, foi uma preocupação que os estudantes pudessem não ter acesso a pacotes de internet e aparelhos eletrônicos necessários e disponíveis para esse tipo de atividade. Levando isso em conta, foi pensado a produção de videoaulas curtas.

O Youtube foi escolhido como plataforma para disponibilizar os vídeos, pois ele apresenta vantagens que iam ao encontro dos objetivos da equipe, tais como: a gratuidade da plataforma; o fácil acesso; e seu amplo conhecimento e uso. Dessa forma, foi aberto um canal no YouTube para o projeto PLAc on-line. A princípio, foram criadas duas playlists no canal: uma com conteúdos voltados ao público adulto (PLAc Adulto) e outra para o público infantil (PLAczinho).

A seguir, vamos relatar com mais detalhes como foi o processo de adaptação ao novo contexto de ensino e as estratégias tomadas para que o ensino chegasse ao nosso público com qualidade. Visando uma apresentação cronológica das ações de 2020 e específica para cada grupo de estudantes, apresentamos as estratégias desenvolvidas no grupo do PLAc Adulto ( $1^{\circ}$ semestre e $2^{\circ}$ semestre) e PLAczinho (não apresentaremos uma divisão entre o PLAczinho Baby e o PLAczinho Maior, pois não houve essa separação na dinâmica de ensino).

\section{PLAc Adulto on-line}

Para a produção das videoaulas para os adultos, a equipe construiu algumas instruções básicas para que pudesse manter um padrão na dinâmica e na disposição das instruções para os estudantes. Foi acordado que as videoaulas deveriam ser curtas, em uma média de 05 a 10 minutos, já que vídeos muito longos poderiam ser uma distração e o tempo de internet dos alunos poderia ser limitado. Na descrição de cada videoaula deveria constar o assunto da aula, um link que direcionava a uma atividade referente ao conteúdo apresentado e o contato de email do professor, que estava responsável por atender as dúvidas e realizar as correções das atividades enviadas pelos estudantes. O envio das atividades contabilizava duas horas de participação do estudante. Ao final do semestre, de acordo com a quantidade de atividades enviadas pelos estudantes, eles recebiam certificação de participação no curso. O certificado 
do PLAc on-line é emitido pelo Centro de Línguas e Desenvolvimento de Professores na Faculdade de Ciências e Letras-CLDP/FCLAr.

Vale destacar que o CLDP já era um parceiro do projeto em sua versão presencial, contudo, no formato on-line se constituiu no principal e único parceiro, concedendo em agosto de 2020 uma bolsa ao projeto para a seleção de uma graduanda de Letras para contribuir com as atividades do projeto. Além disso, o CLDP abrigou o projeto em seu site, oferecendo um espaço para divulgar as informações sobre os trabalhos desenvolvidos.

Retomando as estratégias de ensino, no primeiro semestre de 2020 a equipe elaborou um cronograma prévio para a produção das videoaulas, o que se apresentou como um desafio, pois nas aulas presenciais o projeto contava com turmas divididas por níveis, o que facilitava para selecionar e elaborar os conteúdos apropriados e específicos para cada nível de proficiência e contexto. Já no formato on-line, o desafio foi pensar em um cronograma de conteúdos que abarcasse todas as turmas com seus diferentes níveis de língua e com diferentes maneiras e ritmo de aprender.

Para suprir esse obstáculo inicial, decidimos realizar aulas de temáticas mais gerais, buscando trazer conteúdos que destacassem as principais dificuldades de hispanofalantes durante a aprendizagem da Língua Portuguesa. Além disso, buscamos também trazer a temática da pandemia para as aulas, tentando levar não só uma conscientização da necessidade de isolamento social, mas também uma palavra de acolhimento aos alunos.

As videoaulas eram disponibilizadas inicialmente apenas pelo canal do YouTube, entretanto, foi uma demanda dos alunos que elas pudessem ser baixadas, visto que queriam ter a oportunidade de assistir novamente mesmo quando estivessem sem internet. Como na plataforma YouTube isto não é possível, a solução encontrada pela equipe foi criar também uma pasta na plataforma Google Drive, disponibilizando então as aulas nos dois locais online.

Após a produção das videoaulas iniciais, também surgiu como demanda a necessidade de uma pessoa responsável pela edição e postagem dos vídeos, dado que alguns professores ainda não tinham os conhecimentos necessários para a realização dessas ações. Portanto, um novo voluntário integrou a equipe e trouxe uma nova identidade visual para as videoaulas do projeto.

Como mencionado, o primeiro mês contou com a postagem de videoaulas voltadas para conteúdos gramaticais e fonéticos para o público de hispanofalantes. Entretanto, a equipe de professores sentia falta de compartilhar conteúdos mais diversos que abarcassem também os aspectos culturais da Língua Portuguesa. Para suprir essa necessidade, foram criadas duas 
novas categorias de vídeos: o Português em 3 minutos, que contava com vídeos curtos, específicos para vocabulários, e o Respiro Cultural, no qual eram postados conteúdos culturais da cidade de Araraquara e de todo o Brasil. Com esses novos formatos, o canal se estruturou, portanto, em quatro playlists: PLAc Adulto, PLAczinho, Respiro Cultural e Português em 3 minutos. ${ }^{5}$

Em junho de 2020, o PLAc on-line ganhou uma ramificação e cresceu ainda mais. As coordenadoras do projeto foram contatadas por uma aluna da Pedagogia da UNESP de Bauru, que conheceu o trabalho do grupo no YouTube e solicitou o uso das videoaulas para o acolhimento de um grupo de migrantes que ela voluntariamente atendia na cidade. A partir disso, inicia-se uma parceria entre os dois polos de ensino, em que a professora voluntária de Bauru juntamente com uma outra professora voluntária do projeto organizaram o cronograma de aulas síncronas, que aconteciam aos sábados. O conteúdo foi planejado e ministrado de acordo com os temas das videoaulas que já estavam disponibilizadas no canal. As professoras se utilizavam do conteúdo dos vídeos e elaboravam slides que seriam trabalhados nos encontros síncronos. Os estudantes faziam as atividades disponibilizadas nos vídeos e os professores responsáveis realizavam a correção e devolução por e-mail. Por meio dessa parceria, foram atendidos 22 estudantes venezuelanos.

Ainda neste primeiro semestre, surge entre a equipe do projeto o desejo de ter um contato mais próximo com os alunos, para além das interações que aconteciam no grupo do WhatsApp. Dessa maneira, consultamos os estudantes se eles teriam interesse e condições adequadas para acesso a encontros síncronos. Com a sinalização positiva da maioria dos alunos, propusemos ao grupo de adultos encontros síncronos entre professores e alunos, via a plataforma Google Meet. Ela foi escolhida pelo grupo por ser a de mais fácil acesso que se conhecia até aquele momento, principalmente por não ocupar tanto espaço nos aparelhos móveis dos alunos, uma preocupação naquele momento. Foram então realizados neste semestre dois encontros com os adultos. Neles, retomamos os conteúdos trabalhados nas videoaulas por meio de dinâmicas interativas e utilização de aplicativos on-line, tais como Padlet e Jamboard.

O PLAc on-line certificou de abril a julho de 2020 um total de 28 estudantes e foram produzidos e disponibilizados no canal um total de 43 vídeos: PLAc Adulto (23 vídeos) PLAczinho (14 vídeos), Respiro Cultural (3 vídeos) Português em 3 minutos (3 vídeos).

${ }^{5}$ Endereço do nosso canal no Youtube https://www.youtube.com/channel/UCsCak89JOFrfilvHRNz0-TA. 
Com a experiência advinda do primeiro semestre, a equipe do projeto se reuniu para fazer um balanço das estratégias de ensino utilizadas e percebeu a necessidade de ampliá-las para atender às demandas que identificamos no decorrer dos trabalhos realizados. Desta forma, o PLAc on-line passou por uma reformulação para atender os estudantes durante o segundo semestre de 2020. Para estabelecer um cronograma adequado ao perfil e às necessidades dos estudantes, aplicamos a eles um questionário, em julho, com perguntas tanto em Português, quanto em Espanhol. Obtivemos 49 respostas.

No quadro a seguir, apresentamos o perfil dos estudantes neste segundo semestre de 2020. Este mapeamento foi importante porque, durante o primeiro semestre, muitos alunos novos começaram a acompanhar as aulas e entraram no grupo do WhatsApp por meio da divulgação e recomendação dos próprios estudantes, então precisávamos conhecer este novo público. Com estes dados, notamos que, apesar desses novos alunos que passaram a acompanhar os trabalhos desenvolvidos pelo projeto, o público permaneceu restrito a venezuelanos. A seguir apresentamos um quadro que traz um resumo do perfil dos estudantes do projeto.

Figura 1 - Tabela de perfil dos estudantes do PLAc on-line

\begin{tabular}{|c|c|c|}
\hline Assunto & \multicolumn{2}{|c|}{ Resultado } \\
\hline Gênero declarado & Feminino: 35 & Masculino: 14 \\
\hline $\begin{array}{l}\text { País de origem } \\
\qquad \begin{array}{r}\text { Questão aberta } 49 \\
\text { responderam }\end{array}\end{array}$ & \multicolumn{2}{|c|}{ Venezuela: 49} \\
\hline Status migratório & Residência temporária: 45 & Solicitação de refúgio: 4 \\
\hline Faixa etária & \multicolumn{2}{|c|}{$\begin{array}{c}14 \text { a } 62 \text { anos } \\
\text { (a maior parte está entre } 30 \text { a } 55 \text { ) }\end{array}$} \\
\hline Tem filhos & Sim: 43 & Não: 6 \\
\hline $\begin{array}{l}\text { Pais que residem com seus } \\
\text { filhos no Brasil }\end{array}$ & Sim 39 & Não: 3 \\
\hline Tempo no Brasil & \multicolumn{2}{|l|}{$\begin{array}{l}\text { Recém-chegado: } 1 \\
1 \text { a } 6 \text { meses: } 8 \\
7 \text { meses a } 1 \text { ano: } 28 \\
1 \text { ano a } 2 \text { anos: } 11 \\
\text { Mais de } 2 \text { anos: } 1\end{array}$} \\
\hline $\begin{array}{r}\text { Cidade em que estão residindo } \\
\text { * Questão aberta } 40 \\
\text { responderam (essa questão foi } \\
\text { inserida } 1 \text { dia após o envio) }\end{array}$ & \multicolumn{2}{|c|}{$\begin{array}{l}\text { Agudos 4; Américo Brasilense 4; } \\
\text { Araraquara 6; Bauru 8; } \\
\text { Birigui 1; Cotia SP 1; } \\
\text { Hortolândia 1; Pederneira: 9; } \\
\text { São Carlos 2; São Paulo 3; Venâncio Aires } 1\end{array}$} \\
\hline
\end{tabular}

Fonte: Acervo das autoras 
Também foi importante conhecer o nível que cada estudante tinha da Língua Portuguesa e suas maiores dificuldades durante o aprendizado dela. Para isso, perguntamos aos alunos em que nível eles consideravam que estava seu Português e os dados mostraram que o público se compunha, majoritariamente, de iniciantes na língua, ou seja, nível básico. Quanto às dificuldades, a fala apareceu como a mais desafiadora, seguida de perto pela gramática. O quadro a seguir apresenta estes dados.

Figura 2 - Tabela de nível do Português e maiores dificuldades no aprendizado

\begin{tabular}{|c|c|}
\hline Assunto & Resultado \\
\hline $\begin{array}{l}\text { Nível em que considera o seu } \\
\text { Português }\end{array}$ & $\begin{array}{l}\text { Básico: } 31 \\
\text { Intermediário: } 14 \\
\text { Zero: } 4 \\
\text { Avançado: } 0 \\
\end{array}$ \\
\hline $\begin{array}{l}\text { Dificuldade na língua portuguesa } \\
\text { *Tinham a possibilidade de } \\
\text { marcar todas as opções. }\end{array}$ & $\begin{array}{l}\text { Falar }-33 \\
\text { Gramática- } 32 \\
\text { Escrever- } 21 \\
\text { Compreender- } 9 \\
\text { Ler- } 6\end{array}$ \\
\hline
\end{tabular}

Fonte: Acervo das autoras

Outro dado de extrema importância gerado pelo questionário e que foi levado em consideração no momento de planejar as estratégias de ensino do segundo semestre foram os objetivos e as necessidades expressados pelos estudantes em relação à aprendizagem do Português. A questão proposta era aberta e, assim, os estudantes tiveram maior liberdade para escrever qual seria o objetivo principal em aprender o Português. Para análise, fizemos uma leitura minuciosa dos dados e identificamos alguns objetivos principais, que foram agrupados em seis categorias. A seguir, apresentamos em gráfico as categorias e a porcentagem relacionadas a cada tema.

Figura 3 - Gráfico: Objetivos principais dos estudantes ao realizar o curso do PLAc on-line

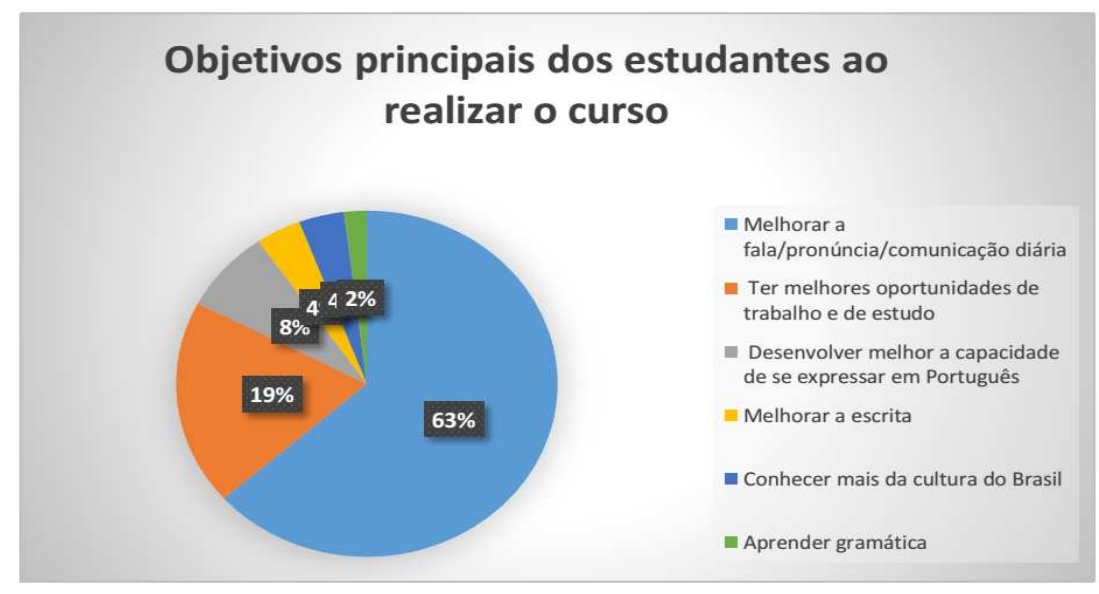


Fonte: Acervo das autoras

Baseado na experiência que tivemos na modalidade presencial do projeto e nas pesquisas já realizadas em PLAc, recorremos à estratégia de ensino dos estudos temáticos para as atividades deste segundo semestre. Assim, estabelecemos uma mesma temática para ser trabalhada durante o mês em todos os âmbitos ofertados - videoaulas e encontros síncronos. Para o estabelecimento dessas temáticas, disponibilizamos aos alunos doze opções de temas para que pudessem assinalar quais destes gostariam de aprender nas aulas. Propomos que escolhessem até cinco temas. O quadro a seguir apresenta os dados desse levantamento.

Figura 4 - Tabela temática escolhida pelos estudantes

\begin{tabular}{|c|c|}
\hline Assunto & Resultado \\
\hline $\begin{array}{l}\text { Temas que foram escolhidos } \\
\text { pelos estudantes } \\
\text { * Os estudantes podiam selecionar } \\
\text { até } 5 \text { dos } 12 \text { temas }\end{array}$ & $\begin{array}{l}\text { Trabalho: } 35 \\
\text { Acesso ao Ensino Superior e cursos de Formação: } 32 \\
\text { Cotidiano: } 26 \\
\text { Finanças: } 26 \\
\text { Culinária: } 23 \\
\text { Arte e cultura brasileiras: } 21 \\
\text { Saúde: } 20 \\
\text { Compras e serviços: } 17 \\
\text { Sistema Educacional para as crianças: } 15 \\
\text { História do Brasil: } 12 \\
\text { Moradia: } 11 \\
\text { Tempo livre e diversão: } 7\end{array}$ \\
\hline
\end{tabular}

Fonte: Acervo das autoras

Tendo em vista as respostas a essa pergunta e os outros dados aqui apresentados, selecionamos as temáticas a serem trabalhadas durante o segundo semestre, a saber: moradia e cotidiano (mês de agosto); trabalho e localização (setembro); finanças e compras (outubro); arte, cultura e culinária (mês de novembro). Vale ressaltar que, para que a maior parte das temáticas selecionadas pudesse ser trabalhadas de maneira satisfatória, optamos por fazer algumas alterações na ordem final apontada pelo questionário.

Assim, agrupamos algumas temáticas que poderiam ser abordadas em conjunto, como "cotidiano", terceira opção entre os alunos, e "moradia", uma das opções menos apontadas. Além disso, a temática "acesso ao Ensino Superior e cursos de formação", escolhida pelos estudantes em segundo lugar, foi selecionada para ser trabalhar em momento posterior, pois a considerávamos um pouco mais complexa e instável para apresentar como se desenvolveria em momento pandêmico. Havia uma instabilidade de retorno e abertura de cursos e vestibulares e, por isso, optamos por esperar e sanar as dúvidas que surgissem no grupo de estudantes de maneira individual. 
Para as atividades realizadas no período de agosto a outubro, foi estabelecida uma sequência de videoaulas e encontros síncronos que se repetia todo mês, visando o trabalho completo das habilidades linguísticas e uma maior coerência nas atividades desenvolvidas ao mobilizar todas as playlists disponíveis no canal do YouTube.

O mês iniciava-se com um vídeo da playlist Português em 3 minutos, no qual apresentávamos os vocabulários que envolviam a temática e dariam insumos para o desenvolvimento dos conteúdos da primeira metade do mês. Em seguida, era disponibilizada uma videoaula no PLAc Adulto, com conteúdo gramatical. Na sequência, um vídeo no Respiro Cultural, discutindo alguma produção artística brasileira. Essa sequência tinha um ciclo de 15 dias. Era, então, realizado o primeiro encontro síncrono do mês, no sábado, e fechava-se a primeira metade do mês com uma nova videoaula para a playlist PLAc Adulto com um conteúdo fonético e fonológico. A dinâmica se repetia, sendo alterado apenas o conteúdo, na primeira parte trazíamos o conteúdo gramatical como foco e na segunda parte dávamos destaque ao conteúdo fonético e fonológico. Para melhor visualizar as estratégias e organização, apresentamos o quadro a seguir com a dinâmica estabelecida.

Figura 5 - Quadro de Planejamento e dinâmica de ensino para grupo de Adultos

\begin{tabular}{|c|c|c|}
\hline AULA & DATA & CONTEÚdO \\
\hline $\begin{array}{l}\text { Português em } 3 \\
\text { minutos }\end{array}$ & Sexta-feira & Vocabulários que envolviam a temática do mês. \\
\hline PLAc Adulto & Quarta-feira & Enfoque em gramática contextualizado com o tema. \\
\hline Respiro Cultural & Sexta-feira & Produção artística brasileira relacionada ao tema. \\
\hline Encontro síncrono & Sábado & $\begin{array}{l}\text { Discussão sobre os conteúdos ofertados nos vídeos e } \\
\text { momentos para tirar dúvidas e estar em contato com os } \\
\text { estudantes. }\end{array}$ \\
\hline PLAc Adulto & Quarta-feira & $\begin{array}{l}\text { Específico para trabalhar com a compreensão e letramento de } \\
\text { gêneros textuais escritos. }\end{array}$ \\
\hline $\begin{array}{l}\text { Português em } 3 \\
\text { minutos }\end{array}$ & Sexta-feira & Vocabulários que envolviam a temática do mês. \\
\hline PLAC Adulto & Quarta-feira & Vocabulário em contexto. \\
\hline Respiro Cultural & Sexta-feira & Produção artística brasileira relacionada ao tema. \\
\hline Encontro síncrono & Sábado & $\begin{array}{l}\text { Discussão sobre os conteúdos ofertados nos vídeos e } \\
\text { momentos para tirar dúvidas e estar em contato com os } \\
\text { estudantes. }\end{array}$ \\
\hline PLAc Adulto & Quarta-feira & Específico para fonética e fonologia do Português. \\
\hline
\end{tabular}

Fonte: Acervo das autoras

Esta estratégia de estabelecer um padrão para as videoaulas e encontros síncronos todo mês foi muito vantajosa tanto para os estudantes, que puderam realizar seus estudos de forma mais estruturada, quanto para os professores, que passaram a, ainda mais, trabalhar de maneira colaborativa para a realização das videoaulas. 
Ressaltamos que o mês de novembro não seguiu a estrutura detalhada anteriormente. Como era o último mês antes das férias de fim de ano do projeto, a equipe decidiu aumentar o número de encontros síncronos neste período, realizando-os todos os sábados do mês. Essa decisão foi tomada depois da observação da grande participação dos estudantes nos encontros que aconteciam quinzenalmente. Os estudantes demonstravam grande interesse nesses momentos de partilha ao vivo e compareciam com assiduidade. Dessa forma, o mês de novembro contou com encontros síncronos toda semana e, no canal do YouTube, eram postados vídeos do Português em 3 minutos e do Respiro Cultural. Todos os vídeos e encontros versaram sobre a mesma temática.

\section{PLAczinho on-line}

O objetivo principal do PLAczinho em sua oferta presencial, de acordo com Sene e Batista (2019), consistia em um primeiro momento proporcionar um acolhimento e um espaço com condições favoráveis à aprendizagem, propiciando um ambiente colaborativo e seguro para que o ensino e a aprendizagem da Língua Portuguesa pudesse ser mediado de acordo com as especificidades de cada faixa etária, respeitando o ritmo de aprendizagem de cada criança. A construção e desenvolvimento das práticas pedagógicas tinham por intuito instigar a curiosidade e a criatividade, bem como a autoconfiança da criança em relação à aprendizagem e aquisição da nova língua (SENE; BATISTA, 2019).

Esses objetivos foram levados em conta ao construir as estratégias para o formato online. Em um primeiro momento, a equipe do PLAczinho selecionou conteúdos mais simples de Português, tais como vocabulários relacionados à casa e verbos de uso cotidiano e fundamentais para compreender ações e instruções para o contexto de prevenção contra a COVID-19. O conteúdo foi ministrado de maneira lúdica e criativa pelas professoras, por meio de contação de histórias e de brincadeiras que instigavam os estudantes a se envolverem e fazerem juntos com seus familiares.

Contudo, percebemos que somente as postagens dos vídeos não estavam possibilitando uma interação adequada com as crianças. Levando isso em conta, a equipe elaborou um formulário para que os pais responsáveis pelas crianças pudessem responder e nos dizer como poderíamos ajudar mais adequadamente seus filhos. Enviamos o questionário no grupo de WhatsApp que tínhamos do PLAczinho, grupo esse que contava com a participação de quatro pais e mães. O questionário tinha por objetivo saber qual a idade das crianças, qual a série escolar em que estavam matriculadas, se estavam tendo aulas on-line e 
como poderíamos ajudá-las com a aprendizagem do Português. O formulário foi respondido apenas por uma mãe, o que não contribuiu muito para pensarmos em estratégias mais específicas.

Decidimos continuar com os vídeos mais lúdicos e convidamos os pais e as crianças para um breve encontro síncrono. Porém, somente uma criança e uma mãe estiveram presentes nesta primeira ação. As tentativas de dialogar com os pais e estar mais próximas das crianças não estavam funcionando. Tentamos conversar pelo próprio grupo e percebemos que havia dificuldade dos pais em acompanhar os filhos, devido à falta de tempo e às prioridades naquele momento serem outras. Normalmente, era um aparelho celular para cada família e isso dificultava a comunicação com as crianças. Os pais, porém, disseram que iriam acompanhar o conteúdo on-line.

Dessa forma, voltamos à estratégia de postagem de videoaulas, entretanto, com uma temática mais definida. As professoras do PLAczinho, com objetivo de tornar aquele ensino prazeroso, curioso e adequado à aprendizagem de aspectos do Português, decidiu conduzir o ensino por meio da leitura do livro "Emília no país da gramática", de Monteiro Lobato. A dinâmica funcionou da seguinte forma: no grupo do WhatsApp as professoras enviavam um áudio com a leitura de um capítulo do livro e, no canal do YouTube, por meio de videoaulas curtas, era explicado o conteúdo gramatical do capítulo.

Essas estratégias e dinâmicas de ensino perduraram de junho a novembro de 2020, quando foi finalizada a leitura do livro. Constatamos pela experiência que a oferta on-line de ensino de Português para as crianças foi um grande desafio e que as estratégias escolhidas e desenvolvidas não nos resultaram em um feedback satisfatório naquele momento devido à dificuldade de interação e contato com as crianças e com os pais.

A seguir, discorremos sobre os dados gerados pelo questionário que disponibilizamos aos estudantes para que pudessem avaliar as estratégias de ensino desenvolvidas no projeto em 2020.

\section{Avaliação das estratégias de ensino pelos aprendentes}

Para que pudéssemos ter um feedback dos estudantes sobre como as estratégias de ensino desenvolvidas pelo PLAc on-line estavam sendo adequadas e pertinentes ao nosso contexto de ensino, elaboramos um questionário com perguntas que visavam investigar diretamente cada ação realizada durante o ano de 2020. O questionário foi disponibilizado em Português, via Google Forms e enviado no grupo de WhatsApp no qual participam os 
estudantes e professores do projeto. Ele ficou disponível do dia 03 de novembro a 07 de dezembro de 2020 e tivemos o retorno de 25 estudantes.

Destacamos que nem todas as questões foram colocadas como obrigatórias para serem respondidas e, por isso, haverá questões que não foram respondidas por todos os participantes. Dessa forma, destacamos nos quadros o número de participantes que responderam a cada questão.

Com o objetivo de trazer uma visão mais completa sobre os dados gerados na avaliação feita pelos estudantes, apresentamos os quadros a seguir que condensam os resultados obtidos.

Figura 6 - Tabela de avaliação do curso PLAc on-line

\begin{tabular}{|c|c|c|c|}
\hline Assunto & Resultado & Assunto & Resultado \\
\hline $\begin{array}{l}\text { Com que frequência } \\
\text { você conseguiu } \\
\text { acompanhar as } \\
\text { videoaulas? } \\
\\
\text { responderam }\end{array}$ & $\begin{array}{l}\text { Semanalmente (18) } \\
\text { A cada } 15 \text { dias (7) } \\
\text { Mensalmente (0) } \\
\text { Raramente(0) } \\
\text { Não vejo os vídeos } \\
\text { (0) }\end{array}$ & $\begin{array}{l}\text { Como você avalia } \\
\text { o conteúdo das } \\
\text { videoaulas para } \\
\text { sua aprendizagem } \\
\text { no Português? } \\
\text { *24 } \\
\text { responderam }\end{array}$ & $\begin{array}{l}\text { Úteis (9) } \\
\text { Bastante úteis (15) } \\
\text { Excelente (1) } \\
\text { Pouco úteis }(0) \\
\text { Nada úteis }(0) \\
\text { Não sei dizer }(0)\end{array}$ \\
\hline $\begin{array}{l}\text { Quais foram as suas } \\
\text { maiores dificuldades } \\
\text { para acompanhar as } \\
\text { videoaulas? Você pode } \\
\text { assinalar mais que uma } \\
\text { opção: } \\
\text { *24 } \\
\text { responderam }\end{array}$ & $\begin{array}{l}\text { Falta de tempo (14) } \\
\text { Conteúdos } \\
\text { desinteressantes (3) } \\
\text { Não se adaptou a } \\
\text { rotina online (3) } \\
\text { Dificuldade com } \\
\text { acesso à internet (8) }\end{array}$ & $\begin{array}{l}\text { Como avalia as } \\
\text { atividades das } \\
\text { videoaulas para } \\
\text { aprender o } \\
\text { Português? Você } \\
\text { pode marque } \\
\text { quantas } \\
\text { alternativas } \\
\text { quiser. } \\
\text { responderam }\end{array}$ & $\begin{array}{l}\text { Útil (16) } \\
\text { Agradável e/ou divertida (15) } \\
\text { Inútil (1) } \\
\text { Simples demais (1) } \\
\text { Chata (0) } \\
\text { Desafiadora (2) } \\
\text { Não sei dizer (0) } \\
\text { Difícil (0) }\end{array}$ \\
\hline
\end{tabular}

Fonte: Acervo das autoras

Os resultados referentes à participação e à avaliação sobre os conteúdos para a aprendizagem e a maneira de aprender o Português nos apontam que, de maneira geral, os estudantes participaram/acessaram semanalmente as atividades e avaliaram o conteúdo e a maneira conduzida para aprender como bastante úteis e agradáveis. Essa percepção foi observada também no grupo de WhatsApp e nos encontros síncronos. A possibilidade de os estudantes terem escolhido quais temáticas gostariam de aprender contribuiu muito para que os conteúdos se tornassem mais adequados às necessidades dos aprendentes. No quadro apresentado, podemos notar que as dificuldades selecionadas pelos participantes estavam em grande parte atreladas à "falta de tempo" e à “dificuldade com acesso à internet”. Dificuldades que já havíamos vislumbrado e que, por consequência disso, optamos por deixar todo o conteúdo das videoaulas disponíveis tanto no YouTube, quanto no Google Drive, para que assim pudessem acessar quando e como desejassem. 
No quadro a seguir, podemos observar os dados sobre a participação dos estudantes na realização das atividades que foram disponibilizadas em cada videoaula.

Figura 7 - Tabela de avaliação do curso PLAc on-line

\begin{tabular}{|r|l|l|l|}
\hline Assunto & Resultado & Assunto & \multicolumn{1}{|c|}{ Resultado } \\
\hline $\begin{array}{r}\text { Você realizou algumas das } \\
\text { atividades das videoaulas? }\end{array}$ & $\begin{array}{l}\text { Sim (23) } \\
\text { Algumas (2) } \\
\text { Não (0) }\end{array}$ & $\begin{array}{l}\text { Como você } \\
\text { recebeu as } \\
\text { correções das } \\
\text { atividades? }\end{array}$ & $\begin{array}{l}\text { Fizemos as correções nos } \\
\text { encontros do dia de sábado (14) } \\
\text { Recebi todas por e-mail (5) } \\
\text { Não recebi nenhuma correção (1) }\end{array}$ \\
responderam & responderam & \\
\hline
\end{tabular}

Fonte: Acervo das autoras

O engajamento desses participantes na realização das atividades foi bem satisfatório, o que nos indica que a disponibilização de atividades para reforçar ou mesmo ampliar a aprendizagem sobre o conteúdo exposto nas videoaulas foi importante para que pudessem praticar o conteúdo e, assim, tirar as possíveis dúvidas nos encontros ou mesmo por e-mail. Foi, também, por meio das atividades recebidas que pudemos compreender se o conteúdo ou mesmo a proposta das atividades estava compreensível aos estudantes e contribuindo com a aprendizagem da língua.

No quadro a seguir, há dados que evidenciam a participação nos encontros e avaliação que os estudantes fizeram sobre esses.

Figura 8 - Tabela de avaliação do curso PLAc on-line

\begin{tabular}{|c|c|c|c|}
\hline Assunto & Resultado & Assunto & Resultado \\
\hline $\begin{array}{l}\text { Com que } \\
\text { frequência você } \\
\text { participa dos } \\
\text { encontros aos } \\
\text { sábados? } \\
\\
\text { *24 } \\
\text { responderam }\end{array}$ & $\begin{array}{l}\text { Participei de todos (13) } \\
\text { Participei de alguns ( } 7 \text { ) } \\
\text { Participei de poucos (2) } \\
\text { Não participei de nenhum (2) }\end{array}$ & $\begin{array}{l}\text { Como você } \\
\text { avalia os } \\
\text { encontros } \\
\text { aos sábados. } \\
\text { Você pode } \\
\text { marque } \\
\text { quantas } \\
\text { alternativas } \\
\text { quiser. }\end{array}$ & 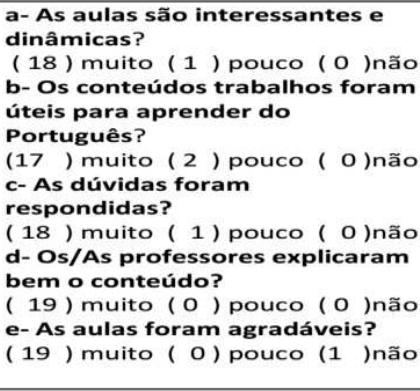 \\
\hline
\end{tabular}

Fonte: Acervo das autoras

A frequência nos encontros era bem instável: havia encontros em que tínhamos a presença de um número maior de estudantes e havia outros que apenas dois a três compareceram. No questionário, fizemos uma pergunta aberta sobre quais eram as dificuldades para comparecer aos encontros síncronos de sábado e os dados nos mostram em 
sua maior parte que as dificuldades estavam atreladas aos seguintes eixos: "falta de tempo"; "estar trabalhando"; "ter compromisso com a família e com a casa"; "não ter memória suficiente no celular"; "não gostar de encontros síncronos". Referente à avaliação sobre os encontros, essa foi positiva nos dados e era perceptível nas próprias aulas. Os estudantes eram muito participativos e se mostraram curiosos para aprender e interagir com os conteúdos mediados nos encontros. Eram momentos agradáveis e de muitas aprendizagens para estudantes e professores.

Por fim, trazemos os dados que apontam como o curso atendeu às expectativas dos estudantes e como esse pôde contribuir para viver no Brasil.

Figura 9 - Avaliação do PLAc on-line curso

\begin{tabular}{|r|l|}
\hline \multicolumn{1}{|c|}{ Assunto } & \multicolumn{1}{|c|}{ Resultado } \\
\hline $\begin{array}{r}\text { De modo geral, como você avalia o } \\
\text { curso PLAC online quanto à suas } \\
\text { expectativas? }\end{array}$ & $\begin{array}{l}\text { Superou minhas expectativas (6) } \\
\text { Atendeu minhas expectativas (14) } \\
\text { Atendeu parcialmente (1) } \\
\text { Esperava mais (0) } \\
\text { Fiquei decepcionado (0) } \\
\text { responderam }\end{array}$ \\
\end{tabular}

Fonte: Acervo das autoras

Pelos dados gerados pelo questionário, notamos que as ações desenvolvidas no projeto foram bem recebidas, atendendo à expectativa da maioria dos que responderam, porém somente esses dados ficam um tanto quanto vulneráveis e questionáveis, uma vez que os estudantes são tão gratos ao projeto que acabam por assinalar as alternativas positivas. No entanto, os dados a seguir da questão aberta nos possibilitam ler e compreender com maior dimensão como o projeto de fato impactou a vida dos estudantes.

Os dados apresentados a seguir, da questão aberta, estão na íntegra, apenas destacamos algumas partes dos discursos em cores diferentes, a fim de organizar e estabelecer categorias temáticas. Pela nossa análise, foram estabelecidas quatro categorias que agrupam, de maneira mais ampla e condensada, as contribuições evidenciadas por meio dos dados sobre como o curso impactou a vida dos estudantes. Elas estão dividas nas temáticas a seguir:

$1^{\mathrm{a}}$ entender, escrever e falar melhor;

$2^{\mathrm{a}}$ relacionar melhor com as pessoas;

$3^{\text {a }}$ comunicar-se e se expressar melhor;

$4^{\mathrm{a}}$ inserir-se no mercado de trabalho e nas práticas socioculturais do cotidiano. 
Figura 10 - Avaliação do curso PLAc on-line

\section{Como o curso tem contribuído com a sua vida no Brasil?}

1- Muito bom. Ajuda a me relacionar com as pessoas

2- Da para entender e falar melhor. Boa comunicação com o semelhante

3- Maior integração y melhor conhecimento na hora de responder alguma pergunta.

4- me ajudou muito a me relacionar com as pessoas

5- Muito aclaro meus dúvidas e poder falar melhor

6- Muito.. Ahora entendo um poco mais o português

7- Muito

8- Pelo curso el tenho aprendido a língua deste país

9- Muito.. Por ele agora posso falar um pouco mais..

10- Ainda não moro no Brasil. Mas acho que tenho muito mais desenvolvimento no portugues na escrita, leitura e fala. Obrigada com os professores e professoras

12-No cotidiano no trabalha em tudo

13- Para conhecer cultura.bom.

14- Quando comença não falava quase nada português..durante as aulas aprendi muitas palabras,frases,cultura brasileira, giras, conjugação de verbos, pronunciaçao etc.,.obrigada

15- Aprendí muito, agradeço pelo esforço dos professores para nós ensinar a língua portuguesa, são excelentes. 16- Meu português melhoro muito com as aulas, arrumar um emprega foi quasi um desafio, os empregadores em algumas ocasões não empregan extranjeros porque eles ficam com medo de não entender a lingua, há um mes tive uma entrevista de emprego e meu empregador me parabenizo por minha fala...eu consegui o emprego.

17- Agora posso escrever e me expressar melhor

18- E muito bom mais é melhor as aulas presenciais

19 -Está ajudando a melhorar minha comunicação com as pessoas.

20- Eles me ajudaram muito

21- Agora é mais fácil falar com as pessoas

22- $\operatorname{Sim}$

23- Meu ayudó muito

24- Por desenvolver em a comunicação

25- agora eu sei mais palavras e expressões que me ajudam a comunicar melhor, eu não tenho mais medo de sair sozinha

Fonte: Acervo das autoras

Além das temáticas identificadas, podemos analisar que os discursos colocam em destaque, no início das frases ou ao longo delas, a ênfase no advérbio "muito" relacionado à intensidade de como o curso pôde contribuir.

Pela análise do conteúdo das mensagens escritas pelos alunos, pudemos ter uma dimensão mais concreta de como o curso impactou as suas vidas e de que maneira pôde atender aos objetivos principais expressados no questionário sobre o perfil dos estudantes. $\mathrm{O}$ gráfico apresentado na seção anterior traz seis categorias que evidenciam os objetivos e necessidades dos estudantes, sendo essas: $1^{\mathrm{a}}$ melhorar a fala/pronúncia/comunicação diária; $2^{\mathrm{a}}$ ter melhores oportunidades de trabalho e de estudo; $3^{\text {a }}$ desenvolver melhor a capacidade de se expressar em Português; $4^{\mathrm{a}}$ melhorar a escrita; $5^{\mathrm{a}}$ conhecer mais da cultura do Brasil; e $6^{\mathrm{a}}$ aprender gramática.

Consideramos que, de maneira satisfatória, os dados sobre a avaliação das estratégias de ensino e aprendizagem que os estudantes declararam ter desenvolvido por meio do projeto foi ao encontro dos objetivos e necessidades que esses alunos apresentaram ter. Assim, o ensino, as estratégias e as práticas pedagógicas desenvolvidas pelo PLAc on-line neste 
momento pandêmico, mesmo com todos os desafios e dificuldades, possibilitaram ofertar um ensino que levou em consideração, dentro do possível e disponível, atender às demandas dos estudantes em aprender aspectos do Português e dos letramentos que envolvem essa línguacultura.

\section{Considerações finais}

Neste texto tivemos por objetivo trazer um panorama das estratégias que o projeto PLAc on-line desenvolveu durante o ano de 2020 e uma avaliação sobre essas pela perspectiva dos estudantes.

A contribuição expressada pelos discursos dos estudantes no questionário de avaliação do curso vai ao encontro do que mencionamos sobre os propósitos de desenvolver o ensino pela perspectiva da Língua de Acolhimento, sendo esses relacionados ao ensino, em primeiro momento, o de desenvolver a capacidade linguístico-comunicativa dos estudantes para que tenham mais autonomia e segurança para se movimentarem, se expressarem e se defenderem na sociedade brasileira. Além disso, o desenvolvimento da competência linguísticocomunicativa, juntamente com o letramento social das práticas sociais interculturais, possibilitou, para alguns estudantes, meios para se inserir no mercado de trabalho e no desenvolvimento das ações cotidianas.

Destacamos que as estratégias de ensino selecionadas e desenvolvidas no projeto foram para atender ao contexto específico de estudantes venezuelanos naquele momento inicial da pandemia. O projeto continua desenvolvendo suas ações de maneira on-line e ampliando cada vez mais a sua oferta e público, assim as estratégias também foram ampliadas e modificadas. Isso nos leva a compreender que o ensino seja de PLAc ou qualquer outro contexto, deve levar em consideração sempre o contexto de ensino, os recursos humanos e físicos disponíveis e, sobretudo, a necessidade de aprender expressada pelos alunos. Esperamos que a experiência e trabalho relatados neste texto contribuam para incitar reflexões e forneçam subsídios para a modalidade de ensino de Português como Língua de Acolhimento em ofertas on-line. 
AGRADECIMENTOS: À equipe do projeto PLAc on-line, ao CLDP, à CAPES, à Faculdade de Ciências e Letras da Unesp de Araraquara e a todos(as) os(as) estudantes do projeto.

\section{REFERÊNCIAS}

AMADO, R. S. O ensino de português como língua de acolhimento para refugiados. In:

Revista da Sociedade Internacional Português Língua Estrangeira - SIPLE, Brasília, v. 7, ano 4, n. 2, 2013.

BARBOSA, L. M. D. A.; BERNARDO, M. D. A. S. Língua de Acolhimento. In:

CAVALCANTI, L. et al. Dicionário Crítico de Migrações Internacionais. Brasília: Editora Universidade de Brasília, 2017. p. 434-437

BARDIN, L. Análise de conteúdo. Trad. Luís Antero; Reto, Augusto Pinheiro. 3. reimp. São Paulo: Edições 70, 2016.

FIORELLI, C. M. et al. O ensino de português língua de acolhimento (PLAc) para venezuelanos no interior paulista: trajetória e perspectiva. In: ROCHA, N. A.; GILENO, R. S. S. (org.). Português Língua Estrangeira e suas interfaces. Campinas, SP: Pontes Editores, 2021.

GROSSO, M. J. Língua de acolhimento, língua de integração. Revista Horizontes de Linguística Aplicada, v. 9, n. 2, p. 61 -77, 2010. Disponível em:

https://www.academia.edu/6956350/L\%C3\%ADngua_de_acolhimento_1\%C3\%ADngua_de_i ntegra\%C3\%A7\%C3\%A3o. Acesso em: 01 jun. 2021.

LOPEZ, A. P. A.; DINIZ, L. R. A. Iniciativas Jurídicas e Acadêmicas para o Acolhimento no Brasil de Deslocados Forçados. Revista da Sociedade Internacional Português Língua, 2018. Disponível em:

https://www.academia.edu/6956350/L\%C3\%ADngua_de_acolhimento_1\%C3\%ADngua_de_i ntegra\%C3\%A7\%C3\%A3o. Acesso em: 25 jun. 2021.

SÃO BERNARDO, M. D. Português como língua de acolhimento: um estudo com imigrantes e pessoas em situação de refúgio no Brasil. Tese (Doutorado em Linguística) Universidade Federal de São Carlos, São Carlos, 2016. Disponível em:

https://repositorio.ufscar.br/bitstream/handle/ufscar/8126/TeseMASB.pdf?sequence=1\&isAll owed=y. Acesso em: 01 jun. 2021.

SENE, L. S Objetivos do ensino- aprendizagem de Português como Língua de Acolhimento. In: MARTORELLI, A. B. P.; SOUSA, S. C. T.; VIRGULINO, C. G. C. (org.). Vidas em movimento: ações e reflexões sobre o acolhimento de pessoas em situação de refúgio. João Pessoa: Editora UFPB, 2020. p. 178- 207. Disponível em:

http://www.editora.ufpb.br/sistema/press5/index.php/UFPB/catalog/book/832. Acesso em: 01 jun. 2021.

SENE, L. S. Materialidades e objetivos para o ensino de português como língua de acolhimento: um estudo de caso. Dissertação (Mestrado em Linguística Aplicada) - 
Universidade de Brasília, Brasília, 2017. Disponível em

https://repositorio.unb.br/handle/10482/23980. Acesso em: 01 jun. 2021.

SENE, L. S.; BATISTA, P. U. PLAczinho: Português como Língua de Acolhimento para crianças venezuelanas. In: ENCONTRO DOS CLDPS,6.; ENCONTRO DO PROGRAMA ISF NO INSTITUTO DE BIOCIÊNCIAS, LETRAS E CIÊNCIAS EXATAS, 1., 2019, São José do Rio Preto. Anais [...]. São José do Rio Preto, SP: UNESP, 2019. (Comunicação oral)

\section{Como referenciar este artigo}

SENE, L. S.; MATOS, T. L. C. Português como Língua de Acolhimento para Venezuelanos(as): estratégias e práticas de ensino em tempos de pandemia. Rev. EntreLínguas, Araraquara, v. 7, n. esp. 6, e021157, dez. 2021. e-ISSN: 2447-3529. DOI: https://doi.org/10.29051/el.v7iesp.6.15490

Submetido em: $23 / 08 / 2021$

Revisões requeridas em: 05/10/2021

Aprovado em: 19/11/2021

Publicado em: 28/12/2021 